Res Pública Revista de Historia de las Ideas Políticas

ISSN: $1131-558 \mathrm{X}$

http://dx.doi.org/10.5209/rpub.67089

\title{
Pensar la política desde la teología y la filosofía: Carl Schmitt y Leo Strauss
}

\author{
José Andrés Fernández Leost ${ }^{1}$ \\ Recibido: 18 de diciembre de 2019 / Aceptado: 22 de junio de 2020
}

Resumen. El contenido de la obra de Carl Schmitt inauguró una nueva especialidad, la "teología política", en la cual se estudia la secularización de los conceptos políticos, en tanto tributarios del pensamiento religioso. En esta línea, Leo Strauss emerge asimismo como pensador centrado en rastrear el impacto de las creencias religiosas sobre la filosofía política. A partir de la comparación de los planteamientos teóricos en ambos autores, el objetivo del texto consiste en interrogarse sobre si la relación conceptual entre la religión y la política resulta inescindible, y sobre si es plausible que la filosofía pueda rebasar el umbral de la teología política, tanto en el terreno de las ideas como en el práctico. Para ello, se examina el "diálogo escondido" que, de acuerdo con las investigaciones de Heinrich Meier, se produjo entre Carl Schmitt y Leo Strauss.

Palabras clave: Decisionismo; fe; liberalismo; soberanía; teología política.

\section{[en] Political Thought from Theology and Philosophy: Carl Schmitt and Leo Strauss}

\begin{abstract}
The content of Carl Schmitt works inaugurated a new knowledge area, "political theology". In this field, research focuses on the secularization of political concepts, which are derived from religious thought. In this sense, Leo Strauss also appears as a thinker focused on the impact of religious beliefs on political philosophy. By comparing both authors theories, our purpose is to explore the relationship between religion and politics, regarding the feasibility that philosophy could transcend political theology in the field of ideas and practices. On this issue, the article addresses the "hidden dialogue" that, according to Heinrich Meier researches, occurred between Carl Schmitt and Leo Strauss.
\end{abstract}

Keywords: Decisionism; Faith; Liberalism; Sovereignty; Political Theology.

Sumario. 1. Introducción. 2. Carl Schmitt: jurista "canónico". 2.1. Soberanía como decisionismo. 2.2. La categoría de la enemistad. 2.3. Schmitt teólogo. 3. Leo Strauss: filósofo escéptico. 3.1. Entre la fe y la razón. 3.2. Hacia un liberalismo esotérico. 3.3. Strauss socrático. 4. El teólogo frente al filósofo. 4.1. El "liberalismo" en Schmitt. 4.2. La religiosidad en Strauss. 5. Conclusión. 6. Bibliografía

Cómo citar: Fernández Leost, J. A. (2020). Pensar la política desde la teología y la filosofía: Carl Schmitt y Leo Strauss. Res Pública. Revista de Historia de las Ideas Políticas, 23(1), 189-202.

\section{Introducción}

El presente trabajo se propone explorar el alcance de la huella religiosa en las categorías que configuran el marco de la reflexión teórico-política contemporánea. En este sentido entra de lleno en la cuestión de la secularización de los conceptos políticos, preguntándose hasta qué punto son tributarios del pensamiento religioso. La amplitud de tal objeto de estudio obliga a acotar el análisis sobre el autor que introdujo, con mayor carga de profundidad, esta línea de investigación durante el siglo XX: Carl Schmitt. En efecto, cabe afirmar que el contenido de su obra inauguró una nueva especialidad, la "teología política", cuya mayor o menor autonomía disciplinar no suspende en todo caso su aportación a la historia de las ideas y las formas políticas. No obstante, el núcleo de nuestro examen consiste en confrontar el planteamiento de Schmitt con el pensamiento de Leo Strauss, no solo como intérprete de aquel, sino como autor asimismo centrado en rastrear el impacto de las creencias religiosas en la conformación de la filosofía política.

A partir de esta comparación -no exhaustiva, circunscrita a cotejar sus visiones sobre una misma materia-, el objetivo consiste en dar respuesta a dos interrogantes, incardinados en el seno de los postulados de estos pensadores: ¿resulta inescindible la relación conceptual entre la religión y la política?, y ¿es plausible que la filosofía pueda rebasar el umbral de la teología política, tanto en el terreno de las ideas como en el práctico? La 
ruta expositiva que se va a tomar se ajusta al siguiente esquema. En primer lugar, se presentará una biografía intelectual de los autores tratados, extrayendo de sus obras aquellos aspectos más relevantes en clave teológico-política. En segundo lugar, se abordará su "diálogo escondido" que, de acuerdo con las investigaciones realizadas por Heinrich Meier, se inició con el comentario de Strauss a la publicación de El concepto de lo político, y en el que el debate sobre la lectura del Leviatán de Thomas Hobbes cobra una relevancia crucial. A lo largo del texto se indagará en la expresión "teología política", perfilando una definición útil para contrastar su empleo por parte de Schmitt y Strauss. Igualmente, en el curso de la exposición se irán identificando las similitudes y diferencias entre ambos autores, y cómo afrontaron las cuestiones citadas. Por último, la parte conclusiva calibrará el encaje de sus obras en el pensamiento político contemporáneo, y examinará sucintamente el estado del debate actual sobre el secularismo ${ }^{2}$.

\section{Carl Schmitt: jurista "canónico"}

Una aproximación introductoria a la obra de Schmitt corre el riesgo de redundar en los tópicos repetidos por el creciente número de intérpretes que viene acaparando este pensador alemán desde su muerte (1985) y, más en concreto, desde principios de los años noventa hasta la actualidad. A efectos de este trabajo, la exposición se centrará en primer lugar en un itinerario cronológico de orden jurídico y se detendrá, a continuación, en una revisión de su obra a la luz del concepto de "teología política”. En rigor, esta lectura resultaría inadecuada, por cuanto el pensamiento de Schmitt está encaminado, casi desde sus primeros escritos, a acentuar la naturaleza matricialmente teológica de los conceptos jurídicos, tanto más habida cuenta de que estos se subordinan a la esfera política. No obstante y sin menoscabo de lo antedicho, se opta por analizar en un apartado diferenciado el componente más "espiritual” de su obra por razones de claridad expositiva, por la propia confesión schmittiana de su mentalidad de teólogo - más que de jurista- en una época ulterior a la II Guerra Mundial (Glossarium) ${ }^{3}$, y por el lugar, asimismo postrero, de la publicación de Teología Política II (1969), texto en el que recupera los conceptos nodales de su pensamiento, en términos expresamente religiosos.

De modo preliminar por tanto, se pasa a repasar el perfil jurídico político de su obra, que cabe distinguir en tres periodos: los años de Weimar, el periodo nacionalsocialista, y los escritos posteriores a 1945. Esta diferenciación puede asimismo producir impresión de arbitrariedad debido a que sus ocupaciones, al menos hasta me-

Desde un punto de vista metodológico, el estudio responde a un tratamiento interpretativo - en sentido lato- que acude a fuentes primarias y secundarias para comprender las ideas de los autores estudiados, sin recurrir apenas a explicaciones contextualistas (socio-históricas o lingüísticas). A ello, insistimos, se agrega un enfoque comparativo flexible, no sujeto a patrones analíticos rígidos, aun guiado por la exploración en paralelo de un conjunto de conceptos clave: decisión, fe, liberalismo, modernidad, obediencia, razón o teología.

Apuntes publicados en 1991, que recogen sus anotaciones entre 1947 y 1958. diado el siglo, giran indistintamente sobre las relaciones entre el Estado y el Derecho y, lo que resulta chocante, sin apenas alteración de su tesis básica: la de la preeminencia de la política sobre la articulación legalista del ordenamiento jurídico. Con todo, conserva pertinencia puesto que permite condensar las dos piezas conceptuales esenciales de nuestro autor en el primer periodo (las de "decisión" y "lo político"); nociones que determinarán toda su producción intelectual ${ }^{4}$. Ciertamente, todavía antes de la I Guerra Mundial se rastrean textos en los que Schmitt se presenta como un joven neokantiano, admitiendo que "el Derecho precede al Estado"s. Sin embargo, ya en 1921 y muy singularmente en 1922 -con la publicación respectivamente de La Dictadura y Teología Política-Schmitt ofrece la base doctrinal que desde entonces definirá su obra: el decisionismo político.

\subsection{Soberanía como decisionismo}

$\mathrm{Su}$ planteamiento recurre a la reformulación de dos términos que, en su visión, aparecen íntimamente conectados: la soberanía y la excepción, según la máxima con la que inicia Teología Política: "soberano es quien decide sobre el estado de excepción". En adelante y bajo un ángulo teórico-político, nuestro autor se dispone a rebasar el alcance del significado de la soberanía, consolidado por la obra de Jean Bodin como fuente de ley (en origen: como poder absoluto), pasando a dotarle de un atributo distintivo que impida que el concepto se normativice, esto es, que la soberanía quede identificada formalmente con la idea de ley fundamental, como cúspide del sistema racional jurídico. En su lugar, propone forzar el concepto hasta presentarlo como una noción-límite inasible desde una reflexión deductivo-lógica. Así, en última instancia, todo orden jurídico se fundamentaría en una decisión factual, precisa, emitida por la voluntad de una figura concreta (personalismo), cuyo carácter es inherentemente político.

La dificultad para entender esta perspectiva es doble: por un lado es necesario apreciar la naturaleza dual de la decisión, en tanto pertenece al orden jurídico -más aún: es "accesible al conocimiento jurídico"6-, pero su materialización se sitúa extramuros de él. Su postura consiste, pues, en supeditar el Derecho a la autoridad estatal, a un poder político preexistente capacitado para revocar, al margen de la norma, el orden institucional, sin dejar de engendrar uno nuevo o restaurado. Por lo demás, tal recalibración del poder modifica la definición del Estado en Max Weber -como instancia que monopoliza legíti-

\footnotetext{
Sin perjuicio de la variación de su enfoque durante el nacionalsocialismo -que pasará a introducir el pensamiento de "órdenes concretas"-, y su apertura a los estudios internacionalistas tras 1945. Efectivamente, como ha señalado uno de sus últimos exégetas (Jean François Kervégan, 2013), cabe apreciar aquí un cambio sustantivo en relación al concepto de Estado, cuya relevancia va perdiendo fuelle conforme pasan los años, hasta que, en la reedición de El concepto de lo politico de 1963, el alemán afirme: "la época de la estatalidad toca ahora a su fin". Ello, huelga agregar, no erosionará la marca del belicismo sobre un mundo globalizado, pero no políticamente universalizable.

G. Gómez Orfanel, "Carl Schmitt y el decisionismo político", en F. Vallespín, Historia de la teoría politica vol. 5, Madrid, Alianza, 2002, p. 234

C. Schmitt, Teología política, Madrid, Trotta, 2009, p. 18.
} 
mamente la violencia-, a otra que pasa a convertirle en la entidad que monopoliza la decisión. El decisionismo schmittiano, según Gómez Orfanel, se adentrará incluso en una suerte de formalismo ciego, enalteciendo la exigencia de la decisión por la decisión, más allá del contenido de la misma; esta tiene valor de por sí, empezando por su virtud para superar la duda en contextos de litigio $^{7}$. La interpretación existencialista del decisionismo, como locus en el que se pugna a vida o muerte por el porvenir de la unidad política, matiza tal lectura formalista: de lo que se trata al cabo es de que la comunidad persevere, toda vez que la suspensión legal se justifica con base al principio de subsistencia.

La tesis decisionista abrirá en el periodo de entreguerras un profuso debate frente al normativismo de Hans Kelsen, donde la actividad estatal se ciñe escrupulosamente al marco jurídico, diseñado bajo el esquema sistemático de una jerarquía piramidal, e inspirado en el positivismo axiomático de David Hilbert. Schmitt reprobó entonces la disolución en la que cae la soberanía cuando se apura tanto la divisoria entre Derecho y Estado, al punto de hacerlos indistinguibles: "Kelsen resuelve el problema del concepto de soberanía -afirmará-, negando el concepto mismo". Por añadidura, el purismo kelseniano abocaría a una concepción procedimentalista de la democracia, levantada sobre el fondo de un pluralismo valorativo que se expresa en las urnas y se ejerce de forma representativa en el parlamento. El razonamiento de Schmitt, en cambio, se distancia del relativismo axiológico, blandiendo la sustantividad que solo se aquilata en el clima de una homogeneidad comunitaria que el parlamentarismo obstruye. Como ha indicado el profesor Manuel Aragón ${ }^{9}$, el propósito de Schmitt no se limita a descartar el parlamentarismo como forma de gobierno, en función de la preponderancia del legislativo sobre el ejecutivo, sino también como forma de Estado, acudiendo a una solución que poco tiene que ver con los sistemas democráticos presidencialistas; a diferencia de estos, su presidencialismo sería dictatorial ${ }^{10}$.

Pero, con independencia del desenlace jurídico-político de la disputa, su raíz se remonta, por definición, al indeterminado supuesto previo del que parte Schmitt: la excepcionalidad; segundo punto de complejidad que entraña su decisionismo. Aquí el interrogante que se suscita es el de si resulta justificado cimentar toda una teoría jurídica sobre la anomalía. El asunto dilata la controversia con Kelsen puesto que en este la teoría se articula y aplica tomando como presupuesto la estabilidad insti-

Punto que entronca con la herencia de los contrarrevolucionarios franceses: "toda autoridad es buena con tal de que exista", aunque aquí también resuene el eco menos dramático de la máxima de Goethe: "prefiero la injusticia al desorden". Aunque desborda el contenido de este trabajo, resulta asimismo imprescindible subrayar la influencia de Donoso Cortés sobre estas cuestiones (explicitadas por el propio Schmitt, Interpretación europea de Donoso Cortés, Madrid, Rialp, 1952).

C. Schmitt, Teología política, op. cit., p. 24

M. Aragón, "La crisis de la democracia constitucional: ¿un pasado que amenaza volver?", Revista de Libros, abril, 2019.

10 Nuestro pensador no declinará en cualquier caso seguir presentándose como demócrata, de acuerdo con una adjetivación "aclamativa"; ahora bien, la reflexión sobre cómo integrar el componente sustantivo a la democracia - de modo que no quepa liquidarla procedimentalmente- todavía colea en el debate contemporáneo. tucional, las situaciones de normalidad. Es conocido el reproche de Schmitt, señalando que dicho enfoque no es operativo en estados de excepción, de ahí la pertinencia de su propuesta. Pero la cuestión es que el decisionismo de Schmitt parece no detenerse en escenarios puntuales de crisis y restablecimiento de un orden, como podría deducirse de su tratamiento sobre la dictadura ${ }^{11}$, de modo que en su caso la excepcionalidad es estructurante y, en lenguaje jurídico, cabría afirmar que su virtualidad se extiende tanto en el momento constituyente como en el constituido, según prueba la prevalencia decisionista en la defensa asimismo del orden constitucional, vale decir: de la política sobre el Derecho. Con todo, este rasgo de excepcionalidad alberga un matiz ambiguo que afecta al poder soberano, en cuanto a los límites de su arbitrio, y seguramente su explicación íntegra no se logre sin aludir al carácter conflictivista, no solo de la mentalidad, sino también del léxico de nuestro autor. Y es que el núcleo de su obra se arraiga en el enfrentamiento de conceptos antagónicos sometidos a una tensión extrema.

\subsection{La categoría de la enemistad}

Esta lógica agonal, vinculada a la prioridad que concede al dominio de la política, configura el preámbulo del texto más influyente de Schmitt: El concepto de lo político (1932). De esta obra también se extrae una sentencia que condensa su planteamiento central - "la distinción política específica [...] es la distinción amigo y enemigo"12 -, si bien la tesis se despliega en varias líneas de argumentación. En primer lugar, Schmitt pretende resguardar el campo de acción autónomo de la política en relación con otros ámbitos de actividad y reflexión humana (económicos, estéticos, morales, etc. $)^{13}$. No obstante, su ambición desborda tal objetivo y termina por subordinar cualquier aspecto de la realidad al patrón de "lo político". El alegato no es complejo: la contraposición "amigo/enemigo" absorbe todo contenido de reflexión o conducta humana por su médula existencial, radicalmente realista. La enemistad se entiende en clave de hostilidad -en puridad: como amenaza ineludible de guerra- poniendo en juego la vida física comunitaria, de forma que la idea de enemigo cumple, en el seno de la política, la misma función que la excepción en el terreno de la decisión.

Tal concepción presupone un pesimismo antropológico de entrada, inextirpable de la condición humana, pero que más que en términos psico-morales, habría que discernir bajo el cariz de su peligrosidad, inspirada por la hipótesis del estado de naturaleza hobbesiano. En consecuencia, la evidencia de una "voluntad de confrontación violenta suficientemente declarada"14 que el clásico inglés caracterizaba como situación límite de la sociedad pre-estatal -anterior a la instauración de la autoridad política-, se prolonga en Schmitt, con la salvedad de que para él, dicho estado de guerra, aun latente, no queda superado; antes bien, representa en su plena

\footnotetext{
O de su invocación, antes de la llegada del III Reich, del artículo 48 de la Constitución de Weimar, que dispensaba poderes excepcionales al presidente.

12 C. Schmitt, El concepto de lo político, Madrid, Alianza, 1999, p. 56. 13 Definidos a su vez por sus propias distinciones internas.

14 T. Hobbes, Leviatán, Madrid, Alianza, 1989, p. 185.
} 
autenticidad la esencia de "lo político"15. Esta interpretación cobra tanto mayor fuste dado que el concepto de "lo político" precede o, cabría sugerir, envuelve al de Estado, sin identificase con él. Ello no es óbice para que Schmitt reconozca que este plasma, como ninguna otra institución, la forma unitaria de "lo político", pero pueden darse otras formas y, más aún, la propia idea de "lo político" desborda con mucho el quehacer del Estado en sus funciones administrativas. De ahí justamente la diferenciación entre la política como espacio de gestión de un orden ya instaurado y "lo político" como espacio en el que se combate por el sentido de la vida colectiva, esto es, por el trasfondo existencial en el que una comunidad se funda o reconstituye. Así, más que en su organización interna, el Estado se aproximaría al alcance "lo político" en el plano de sus actividades exteriores y de defensa, particularmente, cuando se halla en guerra.

La primacía de "lo político" no puede por tanto sino oponerse al lugar secundario -más bien, aséptico y "neutral"- que ocupa la dimensión política en el liberalismo individualista. En efecto, Schmitt enjuicia esta corriente como apolítica, al estar basada en la elusión ética de la violencia y aceptar incluso la predominancia de la economía sobre la política, a causa de la relevancia de la propiedad privada. Esta consideración se extiende en el ensayo sobre La época de las neutralizaciones y las despolitizaciones (1929), donde Schmitt identificaba cuatro "centros de referencia espiritual", que han ido desplazándose en Europa desde el siglo XVI hasta el XX: el teológico, el metafísico, el moral-humanitario y el económico. Ahora bien, la aparente despolitización no sería tal, dicho de otro modo: sería más terminológica que real puesto que la nuclearidad del criterio "amigo/ enemigo" acaba siempre rebrotando bajo nuevas hostilidades. En rigor, la actitud apolítica encubriría una toma de postura política, de manera que no habría manera alguna de evitar la comprensión politizada del mundo. $\mathrm{O}$, valdría decir, la comprensión teologizada. Y es que, llegados a este punto, se hace ya forzoso integrar la lectura religiosa imbricada explícitamente en el pensamiento de Schmitt, al menos desde 1922, cuando afirmó que:

Todos los conceptos centrales de la moderna teoría del Estado son conceptos teológicos secularizados. Lo cual es cierto no sólo por razón de su evolución histórica, en cuanto fueron transferidos de la teología a la teoría del Estado [...], sino también por razón de su estructura sistemática ${ }^{16}$.

\subsection{Schmitt teólogo}

Según esta óptica no resulta arduo detectar las analogías cristianas de las categorías políticas que emplea, observando cómo: la soberanía equivale al poder absoluto de Dios ${ }^{17}$; la excepción se identifica con el milagro; el pesimismo antropológico deriva del dogma del pecado ori-

\footnotetext{
J. L. Pardo, Estudios del malestar: Politicas de la autenticidad en las sociedades contemporáneas, Barcelona, Anagrama, 2016, p. 192.

16 C. Schmitt, Teología política, op. cit., p. 37.

17 No es baladí indicar la adhesión schmittiana a la "potentia Dei absoluta" (que enlaza a Duns Escoto con Hobbes, vía Reforma) frente a la "potentia Dei ordinata" tomista.
}

ginal; el progreso es la faz mundana de la providencia; la oposición "amigo/enemigo" remite a la beligerancia entre Dios y el Diablo y, por ende, la paz perpetua es un imposible político ${ }^{18}$. Sin necesidad de reexponer la perspectiva jurídica previa, la inmersión en la mentalidad schmittiana quedaría incompleta sin acentuar esta mirada, definitivamente aquilatada tras la publicación, 47 años después de su primera parte, de Teología Política II, cuyo subtítulo reza: "la leyenda de la liquidación de toda teología política”. Detenernos en las líneas maestras de esta obra, sobre todo en la réplica que el autor afronta ante las objeciones de Erik Peterson y Hans Blumenberg, es imprescindible para captar el nervio religioso de su pensamiento, pero también para ponderar la longitud de onda y actualidad de una disciplina poliédrica y el grado de similitud -incluso conmensurabilidadque pueda guardar con la teología política en Strauss.

El texto de Schmitt no presenta una tesis inédita sino actualizada de su libro de 1922, y se centra en el análisis del tratado de Peterson, El monoteísmo como problema político, publicado en 1935. En él, se sostiene que el concepto de teología política, según lo planteó Schmitt, carece de recorrido, en virtud de varias razones extraídas de la historia y dogmas del cristianismo. Aun coincidiendo con Schmitt en que la estructura institucional de la Iglesia mantiene similitudes con las formas políticas y procede reivindicar su "naturaleza pública"19, el razonamiento de Peterson retomaba la doctrina de San Agustín, deslindando el orden político del religioso en espacios separados. En consecuencia, resulta imposible tanto fusionar ambos dominios, como supeditar la religión a la política o, en sentido contrario, justificar la monarquía política por la monarquía divina. Peterson evocaba el triunfo del pensamiento agustiniano sobre la argumentación de Eusebio de Cesarea, quien vinculaba el nacimiento y consolidación del cristianismo con el asentamiento del Imperio romano, cristalizado con el edicto de Milán -suscrito por Constantino en el año 313- y la convocatoria del Primer Concilio (de Nicea) en el $323^{20}$. No obstante, el puntal crítico en el estudio de Peterson radicaba en esgrimir el alcance del dogma trinitario, que haría inviable toda forma de cesaropapismo -tanto más en cuanto la Iglesia representa al Espíritu-, a lo que agregaba el horizonte escatológico, de signo extra-político, de la historia sagrada. Es oportuno contextualizar la obra de Peterson en el momento en el que Schmitt abrazó la política nacionalsocialista ( $\sin$ abandonar sus premisas católicas), con lo que aquel se anticipó avant la lettre a las posiciones "cosmopolitas" que se abrirán paso en el concilio Vaticano II.

La envergadura del desafío no intimidó a nuestro autor y si acaso aguzó su talante apocalíptico. Así, en Teología Política II se lanzó a reprobar el paralelismo entre los tiempos de Constantino, cuando la Iglesia se las veía con un emperador filo-cristiano, y el combate existencial que se libraba en 1935 -y aun en 1970- re-

\footnotetext{
M. García Alonso, "Carl Schmitt o la imposibilidad de una política secularizada", Isegoría: Revista de filosofia moral y política, n 32 , 2005 , pp. 235-243.

19 J. L. Villacañas, "La leyenda de la liquidación de la teología política”, en C. Schmitt, Teología política, op. cit., p. 148.

20 Su proclamación como religión oficial no se produjo hasta el año 380, bajo Teodosio.
} 
pleto de enemigos "completamente desteologizados"21. Dejando de lado la disputa trinitaria, que Schmitt despacha reinterpretando el misterio como una ilustración conceptual del conflictivismo político -de oposición "amigo/enemigo"- la clave de su discurso reside en la infiltración decisiva del factor histórico, que mezcla ambas esferas y desemboca en la pérdida del monopolio de lo religioso por la Iglesia, y de "lo político" por el Estado: la historia, pues, no haría sino desactivar una demarcación ficticia, toda vez que además lo religioso y "lo político" anteceden a sus formas institucionales. Siguiendo con esta línea de razonamiento, Schmitt admite la circunscripción extra-política en el que se enclava el reino de Dios, de acuerdo con el relato escatológico, pero no renuncia a enfatizar el papel de un Estado redefinido, resacralizado, que asume la estructura y propósito de la Iglesia -ya políticamente inútil- en la realidad concreta de una historia previa al fin del mundo. Frente a la deriva universalista del catolicismo post-conciliar, auto-suicida en tanto acabará licuado en el secularismo liberal (según interpela Ernst-Wolfgang Böckenförde), se requiere la presencia de una instancia que vindique su emplazamiento espacial y haga frente al desorden inexorable de la historia. Mientras esta dure, persistirán las hostilidades de un enemigo que, en último término, remite al Anticristo; de ahí al fin la necesidad de recuperar la noción de katechon: una fuerza real, histórica - una suerte de Leviatán hobbesiano, ya no protestante, sino católico $^{22}$ - que detenga dicha amenaza.

Con aliento menos épico, pero similar mordiente analítica, Schmitt reservará su epílogo a contrarrestar la tesis de Blumenberg, emitida por su parte desde un prisma científico. En La legitimación de la edad moderna (1966) Blumenberg examinó la secularización teológica a partir de su metaforología, aludiendo a una transposición conceptual meramente "funcional" ${ }^{23}$, no sustantiva. Ahora bien, al margen de este reajuste lingüístico, la idea central recae en la relevancia que cobra la ciencia en la evolución hacia una modernidad abierta al progreso, gracias a la cual la humanidad autoafirma su autonomía, prescindiendo de la aspiración de trascendencia. Aceptando de pleno su coherencia, Schmitt apenas alterará su mirada ${ }^{24}$, afrontando el reto de Blumenberg con una sen-

C. Schmitt, Teología política, op. cit., p. 85.

2 De algún modo prefigurado en Catolicismo romano y forma política. 3 A. Galindo Hervás, “¿Autonomía o secularización? Un falso dilema sobre la política moderna", en R. Mate y J. A. Zamora, Nuevas teologías políticas: Pablo de Tarso en la construcción de Occidente, Madrid, Anthropos, 2006, p. 135.

24 En la interpretación de J. L. Villacañas ("La leyenda de la liquidación de la teología política", op. cit., pp. 173 y ss.), el análisis de Blumenberg afecta ante todo a la obra de Eric Voegelin, en parte dirigida a denunciar la ilicitud de las "transferencias de significado" y el carácter gnóstico de la modernidad-reimpulsado por la Reforma- en la que el humanismo, la Ilustración o el progresismo constituyen movimientos inmanentistas que pretenden salvar al hombre en la Tierra y que oscurecen "la conciencia de sacramentalidad del mundo" (A. Galindo Hervás, op. cit., p. 128). El argumento de superación de la gnosis por parte de Blumenberg no deja de resultar paradójico. El postulado de la potencia absoluta de Dios en Escoto habría sido tan radical (superando los filtros de toda razón), que habría terminado por debilitar no solo el conocimiento teológico sino la propia fiabilidad de Dios. Así: "la provocación del absoluto trascendente, cuando se radicaliza hasta su punto máximo, se transforma en el descubrimiento del absoluto inmanente" (A. Rivera García, "Secularización cilla argumentación apagógica, es decir: devolviéndole a este su misma contra-imagen inmanente de la realidad (des-teologizada) e interrogándose, ya ni siquiera sobre su verdad sino sobre su deseabilidad, reintroduciendo por fin el ingrediente interno de la hostilidad en el seno del humanismo. Se pasaría así del principio de Goethe ("nada contra Dios excepto Dios mismo"), al actual: "nada contra el hombre sino el hombre mismo"25.

En suma, Schmitt cartografía los rudimentos de una disciplina, no inédita en su expresión, ni siquiera en su intuición original, en tanto la teología política se entiende como "una doctrina política que asegura estar basada en la fe de la revelación divina"26, pero que sí lo es en relación a su toma de conciencia como arma de batalla, o auto-afirmación - casi se diría que orgullosa- del orden frente a la anarquía. No en balde Schmitt asume como referencia inmediata el uso de esta expresión en Mijaíl Bakunin, desde el cual se lanza a recalcar la sustantividad metafísica de las ideas políticas, que aparecerán sistematizadas bajo tres conceptos básicos: la autoridad, la revelación y la obediencia.

\section{Leo Strauss: filósofo escéptico}

La reexposición del pensamiento de Strauss afronta por su parte las complicaciones propias de un autor que nos ha legado una obra asistemática -dispersa en artículos y monográficos recopilados posteriormente en forma de libros-, fundamentada ante todo en una lectura aguda e inédita de la filosofía clásica y medieval, y que carece de una tesis doctrinal definida, a lo que se agrega un estilo expositivo que no ayuda a esclarecer sus postulados. No por ello resulta inadecuado subrayar un conjunto de rasgos asociados a su visión: la reflexión reiterada sobre los vínculos entre Atenas y Jerusalén, la reivindicación de la actualidad del pensamiento platónico -tamizada por la recepción judía y musulmana-, y la crítica ante el declive de Occidente, derivada del triunfo de la Ilustración, y anticipada en la obra de Hobbes y Baruch Spinoza. Por descontado, el contexto histórico en el que se formó, marcado por la crisis de la República de Weimar y el auge del antisemitismo, así como su posterior instalación en Estados Unidos contribuyen a explicar el tono de sus intereses intelectuales. No obstante, pese a compartir la misma experiencia de muchos intelectuales alemanes, con Strauss nos encontramos con una figura atípica, aislada y, no solo por carácter, sino por la excentricidad de su obra.

De manera más cronológica que temática, cabría dividir su pensamiento en tres etapas, la de sus primeros escritos en Alemania (década de los años treinta); la etapa centrada en sus años en Chicago y, por último, la de sus textos que salen a la luz tras la publicación de La ciudad y el hombre (1964). Esta ordenación no

y crítica del liberalismo moderno", Revista Isegoría n 39 (juliodiciembre), 2012, p. 243.

25 Que también nos evoca a Gregorio Nacianceno: "Lo uno está siempre en rebelión contra sí mismo".

26 H. Meier, “¿Qué es la teología política?: introducción a un concepto controvertido", La Torre del Virrey: revista de estudios culturales, $\mathrm{n}^{\circ}$ 6, 2009, p. 91 . 
hace justicia a un tratamiento conceptual, en tanto que Strauss vuelve una y otra vez sobre los mismos tópicos, empezando precisamente por el de su predilección hacia el "problema teológico-político", que le acompañará toda su vida ${ }^{27}$. En efecto, desde su juventud nuestro autor iniciará bajo el ascendiente de su filiación judía una aproximación hacia las relaciones entre religión y política, defendiendo con rotundidad la opción por un sionismo político distanciado de las tendencias liberales (asimilacionistas) del judaísmo neo-kantiano. Ahora bien, la originalidad de Strauss consistirá en defender la vigencia de la tradición ortodoxa, por cuanto aunque no es posible racionalizar la revelación (la ley es obediencia), tampoco sería posible dar sustento racional a la fe en la razón ${ }^{28}$.

\subsection{Entre la fe y la razón}

Esta perspectiva adoptará un carácter más articulado en su ensayo La critica de la religión en Spinoza (1930), donde Strauss reprueba la convicción del filósofo neerlandés de que la naturaleza es inteligible y de que es factible instaurar sociedades políticas que integren a miembros de distintas confesiones religiosas, entroncando con un iusnaturalismo cristiano que allanará el camino a la Ilustración. En este sentido, la crítica straussiana se puede condensar en dos puntos: la creencia de que el Todo (llámese Dios, llámese Naturaleza) resulta aprehensible, y la presunción coextensiva de que el conocimiento filosófico prevalece tanto en el plano de la vida teórica como en el de la vida práctica, cristalizando en el triunfo del proyecto ilustrado. Ante ello, Strauss recuperará el enfoque veterotestamentario -que coincide a su juicio con el punto de vista socrático e incluso calvinista- de que el Todo es incognoscible ("solo sé que no se nada") y de que permanece misterioso y oculto. De ahí precisamente que la filosofía esté permanente abierta a interrogantes perennes, de algún modo trans-históricos. Tal conclusión nos proporciona una primera pista sobre el "judaísmo ateo" de Strauss, puesto que su anclaje en la ortodoxia no obedece a una mentalidad creyente, sino a la intuición de que existe un ámbito de pensamiento supra-religioso o, vale decir, supra-político. La cesura entre ambas dimensiones rebasa el debate teológico-político pero resulta crucial para entender el papel ambiguo, pero determinante, que le corresponderá a la filosofía política. Acudir a Filosofía y ley (1935), libro en el que nuestro autor retoma el racionalismo medieval (premoderno) de Maimónides nos sirve de apoyo para desentrañar esta cuestión.

Aquí Strauss nos invita a una interpretación a contracorriente del clásico judío, en tanto el nivel subsidiario en el que en apariencia se ubicaba la razón, frente a la religión, queda ahora matizado. El tratamiento straussiano analiza la síntesis entre ambas esferas partiendo de una noción primigenia de ley, como código relevado y divino, infundamentado racionalmente. En virtud de este

\footnotetext{
Sin perjuicio de la persistencia temática, en Strauss sí que se aprecia la introducción de nuevos enfoques a medida que su obra avanza.

28 En lo que sigue, nos atenemos como hilo conductor a la biografía que Gregorio Luri dedicó a Strauss, con el título Erotismo y prudencia, Madrid, Encuentro, 2012.
}

punto de partida, de lo que se trataría es de justificar racionalmente la religión pero admitiendo, a su vez, que la actividad filosófica se funda en la preexistencia de la ley. La filosofía se ejerce, pues, en un contexto necesariamente religioso aunque $-\mathrm{y}$ he aquí la clave- esta conserva (o quizá sea mejor decir, adquiere) una desenvoltura autónoma tal que su desarrollo desborda todo perímetro creencial. La argumentación de Strauss se resolverá en el reconocimiento explícito de que toda sociedad requiere de un sólido sistema moral (religioso-político) para sobrevivir, exigencia de la que el filósofo es plenamente consciente, aun no compartiendo tales creencias.

Bajo este ángulo, la figura del profeta asume la función platónica del filósofo-rey, orientando a la comunidad. Es más, el influjo de Platón se convertirá en un punto de referencia permanente en el pensamiento straussiano (como verdadero fundador de la filosofía política), mediado por la exégesis judeo-musulmana, como se ratificará, diez años después, en el "Platón de Alfarabi" (1945): un texto en el que nuestro autor insiste en la diferencia "de grado" entre filosofía (como reflexión en la que está permitido cuestionarlo todo, incesantemente escéptica) y la filosofía política, ceñida al tratamiento de las "causas nobles y justas", y que evoca al tiempo la prudencia de Platón tras el trágico destino de la transparencia y sinceridad socrática. En esta línea, cabe adelantar que en Strauss: "la filosofía política no es sino eso, la presentación en público de la filosofía" ${ }^{29}$. El arte de manejar un doble lenguaje, por parte del pensador político, dará pie a la distinción entre el cultivo de la escritura exotérica y esotérica, en el que Strauss profundizará al asentarse en Estados Unidos.

Pero antes de pasar a estos años es preciso recuperar una última obra de sus "primeros escritos", igualmente decisiva en el marco de este trabajo: La filosofía politica de Hobbes (1936). Ciertamente, parte de la polémica que Strauss mantendrá con Carl Schmitt girará justamente en torno a la correcta lectura del pensador inglés, que en nuestro autor va a estar enteramente asociado al nacimiento del liberalismo moderno. Sobre el Leviatán cargará los defectos que ha venido arrastrando este pensamiento político, toda vez que en la obra de Hobbes ya se encuentran sus principales indicios: la premisa de que se puede conocer y someter a la naturaleza, la irrelevancia de todo ideal ético comunitario como fundamentación de la autoridad, o la preeminencia del criterio de supervivencia individual y, por ende, del egoísmo utilitario como clave de comprensión de la política. Se inicia así la corriente cultural de la modernidad -en la que después Strauss incorporará a Maquiavelo, como "maestro del mal"-, donde el historicismo, el positivismo y la apelación a los instintos más primarios de la humanidad, pasan a ocupar el primer plano de la reflexión política.

A título anecdótico, guarda relevancia mencionar la firme impronta conservadora, tendente al autoritarismo, que en los años treinta todavía manifiesta Strauss, según se desprende de su carta a Karl Löwith:

El hecho de que la nueva derecha alemana no nos tolere no dice nada contra los principios de la derecha. Al contrario:

F. Vallespín, "La vuelta a la tradición clásica", en F. Vallespín, Historia de la teoría política vol. 5, Madrid, Alianza, 2002, p. 357. 
solo a partir de los principios de la derecha, es decir, a partir de principios fascistas, autoritarios e imperiales es posible de una manera digna [...] protestar contra la mezquina abominación ${ }^{30}$.

Sin embargo, estas tendencias se irán moderando conforme nuestro autor penetre en la atmósfera, tradicionalista pero tolerante, del mundo anglosajón y fije su residencia finalmente en Estados Unidos, primero en Nueva York y posteriormente en Chicago (donde profesará hasta 1969).

\subsection{Hacia un liberalismo esotérico}

Durante tres décadas, Strauss desarrollará una producción académica notable, en la que -sin menoscabo de otros artículos y monográficos-, sobresalen dos textos: Persecución y arte de escribir (1952) y Derecho natural e historia (1953). Pese a su publicación posterior, es pertinente detenernos antes en este último libro (fruto de las conferencias Walgrene que impartió en 1949) por cuanto ha sido calificado como la obra central de Strauss, y se convirtió en el manual de cabecera de su escuela. El título es indicativo del propósito de Strauss; no obstante contiene una defensa heterodoxa de lo que se entiende por iusnaturalismo, que afecta de lleno a su concepción del historicismo. Así, aunque en su arranque invoque la Declaración de Independencia de EEUU, bajo el soporte de la existencia previa de unos derechos individuales inalienables y, es más, haga equivaler el rechazo de esta doctrina con el triunfo del nihilismo, lo que en rigor defiende Strauss es la primacía de un derecho natural antiguo frente a su desviación moderna. Más aún, en primera instancia lo que se propone es, más que presentar un tratado definitivo, ofrecer una visión propedéutica del tema ${ }^{31}$.

Por supuesto, Strauss prolonga su decantación hacia la mirada antigua de la naturaleza, en donde esta persiste escondida y resulta impredecible, frente al enfoque moderno en el que es accesible, manipulable y obedece al patrón de la lógica. Con todo, debe constatarse cómo Strauss sí que detecta en la filosofía antigua una teleología innata, de cuño aristotélico, que impulsaría al hombre a encaminar su actividad de forma natural hacia los fines más elevados y virtuosos ${ }^{32}$. Tal consideración, inherente a la esencia humana, queda preservada siempre que a su vez se conserve la cautela de admitir su componente idealista -o de ideal regulador-, contrapesado por la incertidumbre que depara la ininteligibilidad última del mundo. La crítica se reserva, pues, a la idea del derecho natural moderno que invierte la perspectiva

\footnotetext{
30 Donde, como anota G. Luri, la "abominación” es el nazismo. G. Luri, op. cit., p. 134.

31 Ibidem, pp. 254-255.

32 Este aristotelismo nos parece crucial para presentir el lugar que, frente a la política, viene a ocupar la filosofía en Strauss. En la Ética a Nicómaco (quinto capítulo del libro sexto) leemos: "La sabiduría es un compuesto de la inteligencia y de la ciencia, y que es, puede decirse, la ciencia de las cosas más elevadas, la cual está a la cabeza de todas las demás ciencias. En efecto, sería un absurdo creer que la ciencia política, o la prudencia política, es la más alta de todas las ciencias, si no se creyese al mismo tiempo que el hombre de que se ocupa es lo más excelente que hay en el universo".
}

antropológica, tomando como referencia al individuo en su nivel inferior, aquel en el que se encuentra en el "estado de naturaleza" hobbesiano, donde se privilegia su apego a la supervivencia y la seguridad. Ahora bien, la innovación nuclear de Derecho natural e historia se localiza en el señalamiento de la escolástica tomista como verdadero punto de inflexión del concepto de naturaleza, en tanto esta sería comprensible por medio de la razón humana, lo que implica la capacidad de deducir las leyes naturales que gobiernan el mundo, incluyendo las que se extienden a la regulación de la sociedad. Dicho presupuesto abrirá la senda de una suerte de naturalismo racionalizado (avalado por Dios) que acabará abonando la emergencia, no solo del liberalismo individualista en el que los derechos del sujeto priman sobre el bien común-, sino también del historicismo y del cientificismo que impregnarán la mentalidad moderna (téngase en cuenta el influjo del neo-tomismo, representado por figuras de la talla de Jacques Maritain, en la declaración de los Derechos Humanos).

En la estela de esta obra, Strauss clarificó el sentido e impacto de la modernidad en un texto publicado de forma póstuma, "Las tres olas de la modernidad" (1975), que ampliaba la tercera parte de su libro ¿Qué es filosofía política? (1959). El corte con la antigüedad consiste en revertir la noción de la naturaleza de modo que esta pasa, de ser un límite para el conocimiento, al objeto del mismo, tesis que en los últimos cuatro siglos habría quedado apuntalada en ráfagas concatenadas que, aun incompatibles entre sí, confinan en el olvido el significado genuino de la physis. Dicha cesura en puridad la habría inaugurado el amoralismo técnico de Maquiavelo ${ }^{33}$, depurado por el materialismo mecanicista de Hobbes, que se aplica precisamente sobre al estudio de la política. El subsiguiente giro moralizante, en Jean-Jacques Rousseau o G.W.F. Hegel, aun de signo comunitario, no vino sino a eclipsar definitivamente el influjo de la naturaleza sobre la reflexión filosófica, transfigurada desde entonces en filosofía de la historia, esto es, en un relato lineal, racional, ascendente y progresivo cuyo final redentor -en tanto cristianismo secularizado- equivale a trasladar la fe en el cielo a la tierra. La última oleada moderna adviene con el existencialismo nietzscheano, cuyo irracionalismo no le exime de recurrir a un principio, el de la voluntad de poder, que ignora toda resistencia natural y ha de envolver, aun en todo su sinsentido, la reiteración de la historia de acuerdo con la doctrina del eterno retorno.

Estas conclusiones nos sitúan en la antesala de un Strauss que, en la última década de su vida, retorna al pasado para ofrecernos la solución de un liberalismo antiguo, que reajusta la pertinencia creencial (teológica, en un sentido lato) de la filosofía política-incluso haciéndo-

\footnotetext{
Sin ánimo de exhaustividad, resulta ineludible referirse al libro, Meditaciones sobre Maquiavelo (1958) en el que Strauss corrige su juicio sobre Hobbes, endosando al florentino la responsabilidad primordial de la ruptura con la tradición, ilustrada en la imprudencia de su lenguaje, la dignificación del pesimismo antropológico, la secularización de los mitos que acompañan a la fundación de todo nuevo orden político y la introducción de una noción ambigua de la naturaleza (como "fortuna" indescifrable) pero que un hábil estratega puede llegar a domeñar (G. Luri, op. cit., pp. 281-290).
} 
la compatible con la democracia contemporánea- y que todavía concede margen a las enseñanzas de Friedrich Nietzsche, más que a las de Martin Heidegger. Previamente, es preciso recuperar el alcance hermenéutico de su obra Persecución y arte de escribir (1952), imprescindible para captar su método de aprendizaje y de enseñanza, y las constantes relecturas que afinan su comprensión de los textos clásicos. Como se ha avanzado, la clave explicativa se halla en la distinción entre los estilos esotérico y exotérico de escritura. Nuestro autor sugiere que los grandes filósofos siempre han recurrido a este doble lenguaje, en parte accesible, en parte encriptado, por varios motivos. En primer lugar, para escapar de la censura o de la persecución, que experimenta -con mayor o menor intensidad- el pensamiento crítico en cualquier lugar y época.

Sin embargo, existe otra razón más recóndita que consiste en la deliberada necesidad del filósofo de camuflar el contenido real de su mensaje, debido a la peligrosidad de sus implicaciones. Desde un punto de vista metódico, el estilo esotérico obliga al lector a un esfuerzo paciente y tenaz por extraer acertadamente la verdad encubierta y "desarmada" encerrada en la obra, es decir, a una lectura entre líneas destinada a comprender el texto tal y como lo comprendía el propio autor, por muy ingenuo que esto parezca. De ahí que a la metodología straussiana de estudio se la califique como "textualista", desestimando la línea de interpretación contextual. En consecuencia, al filósofo contemporáneo también se le exigiría el ejercicio de esta suerte de hermetismo ("perverso"), que algunos críticos aprecian en la propia obra de Strauss. Al margen de estas consideraciones, el atractivo que suscita este proceder es que conecta con los postulados teóricos de nuestro autor, toda vez que la figura de cualquier filósofo resulta políticamente incómoda (si es que resguarda su vocación escéptica e intuye que la verdad puede ser desagradable) y en su vida práctica, como filosofo político, ha de adoptar un perfil cauto, reconociendo incluso la conveniencia de las "nobles mentiras" por el bien de la comunidad. Pues bien, esta óptica esotérica llevó a Strauss no solo a matizar sus conclusiones sobre el legado de Maquiavelo o Spinoza, sino a ahondar en el análisis de la herencia socrática, releyendo en los trabajos de Tucídides, Jenofonte o Platón el gradual pulimento de una sabiduría prudencial, ya olvidada.

\subsection{Strauss socrático}

Cabe situar el preludio del "último Strauss" en la publicación de La ciudad y el hombre (1964) ${ }^{34}$ en donde, además de reiterar las divergencias entre el ciudadano y el filósofo a la hora de meditar sobre la ciudad, sobre la vida en común, enfatiza el protagonismo pedagógico de los poetas, asunto que cobrará importancia creciente en el tramo final de su vida. No hará falta insistir en el plano pre-filosófico en el que Strauss sitúa la percepción ciudadana, subordinada a la religión - a las creencias, a la ley en su sentido revelado- a fin de reafirmar la consistencia de la ciudad, el soporte mítico que dota de justificación y valor a su

\footnotetext{
34 Algunos especialistas trazan el corte en 1967, como por ejemplo J. García-Morán Escobedo, "Presentación”, en ¿Qué es filosofia politica?, Madrid, Alianza, 2014.
}

existencia. Aunque estén en ella, los ciudadanos no se percatan de que viven en la caverna, pero tampoco necesitan ser filósofos, y sus dioses ("olímpicos") les resguardan del caos de la physis (que en ocasiones se manifiesta bajo forma de guerra): les protegen de lo absolutamente incomprensible, de lo "totalmente otro" -quizá el Dios de los judíos, o el de Calvino, quizá los dioses "cósmicos"-, de algo a lo que jamás se accederá.

Ya Tucídides, en la perspectiva de Strauss, expone esta realidad desde un discurso histórico que incide en la afinidad del hombre corriente hacia su comunidad y a la prioridad que confiere a sus necesidades cotidianas. Pero esta apelación a Tucídides -a nuestro parecer- abre paso en el pensamiento de Strauss al relieve político que va depositar sobre la figura del poeta como puente entre la sabiduría filosófica y la prudencia política. Sin perjuicio de la distinción aristotélica ${ }^{35}$, los poetas -como los historiadores-, ordenan y narran el mundo, le otorgan sentido y estructura, aun intuyendo su impenetrabilidad; dominan en suma los recursos del lenguaje y, así, Aristófanes recurre a la comedia, o Lucrecio al lirismo, para educar al ciudadano. La poesía cumple una función pedagógica básica en el terreno de la política que, por su parte, el Platón de Las Leyes vuelca sobre la religión como dimensión neurálgica de su legitimidad $^{36}$. En este punto debe retomarse la concepción legal platónica, no como deducción natural, sino como norma fundacional creencial pre-filosófica, que permitió en el medioevo el desarrollo de la teoría política judeo-musulmana. Leo Strauss, con todo, no desconoce el troquel artificial que toda legislación adquiere a ojos de Platón: incluso reconociendo su imperatividad en la esfera pública, ello no altera la prevalencia de la filosofía.

De acuerdo con lo dicho, cabe sostener la prosecución de una tensión no resuelta en la obra straussiana, entre la sabiduría racional y la prudencia política, que ilustran sus últimos comentarios sobre "el problema de Sócrates". Sin duda el desparpajo de la actitud socrática, explícitamente racional, repudiando los mandatos religiosos, encarna la del enemigo de la ciudad, aunque, siguiendo el comentario que Strauss le dedicó al Económico de Jenofonte, en Sócrates también se descubre una propensión a adornar y "cosmetizar" el mundo ${ }^{37}$, a hacer "presentable" el conocimiento filosófico y ¿no era esa precisamente la labor primera de la filosofía política? El "problema de Sócrates", como trasgresor desvergonzado, no se resuelve, pero su obra queda como inmediato precedente del pensamiento político y del racionalismo clásico. La referencia a un mundo presocrático que nos devuelva a una reflexión sobre el ser, descontaminada de su contexto histórico y auto-consciente de su subsistencia frente al cambio, desemboca en una filosofía apolítica ("absoluta"38) o, a lo sumo - como viera Nietzsche- en una resolución decisionista, anclada en la voluntad de poder que ha asumido la indiferencia de la physis inescrutable. Consciente de sus implicaciones, pero no sin admiración, Strauss adivina en la "ilusión heroica" del judaísmo una señal de esta acti-

\footnotetext{
Sobre las diferencias entre la poesía y la historia argumentada en su Poética.

36 Huelga recordar el juicio que le merecen los poetas a Platón; ahora bien: más que nada por el trato que asignan a los dioses.

7 G. Luri, op. cit., p. 337.

38 Como sucede en Heidegger.
} 
tud, pero al cabo no renuncia a su escepticismo socrático; los interrogantes más elevados -las cuestiones perennes de la vida filosófico-teórica- nunca se resolverán. Acaso la evolución ideológica de Strauss capture su íntima toma de postura, ligada a la defensa de la democracia liberal -de un liberalismo conservador, disciplinado, deferente ante las tradiciones, valedor de las virtudes clásicas- quizá porque lo considere el sistema que mejor protege la individualidad privativa del filósofo cuando da rienda suelta a sus cavilaciones extra-políticas, siempre racionales, en absoluto teológicas.

\section{El teólogo frente al filósofo}

La comparación entre el pensamiento de Carl Schmitt y Leo Strauss no deja de tener un cariz extravagante. En un primer cotejo, más allá de algunas similitudes episódicas y de superficie, pudiera parecer que sus obras no permiten un contraste justificado de sus tesis. Ciertamente nuestros autores atestiguaron con actitud crítica el declive de la República de Weimar, inclinándose hacia posturas conservadoras: en ambos se percibe una impugnación hacia la modernidad, esto es, hacia el positivismo y el historicismo derivados del liberalismo fundacional del siglo XVII. Igualmente en ambos casos se contempla un fondo teórico tensional que fuerza a que todo razonamiento político se dirima por una voluntad de tipo decisionista. No obstante, ampliando el foco de análisis, se observa a dos autores cuyo recorrido intelectual tan solo confluye incidentalmente y cuyos intereses epistemológicos, métodos de investigación, convicciones, principios e inferencias teóricas apenas coinciden.

En apariencia, poco se puede extraer de la confrontación entre un perfil jurídico anclado en los dogmas cristianos, con el de un filósofo de ascendencia judía interesado en recuperar las lecciones de la sabiduría pre-cristiana. Con todo, el relieve político que Schmitt y Strauss conceden a la teología, así como el magnetismo de la obra de Hobbes como referencia de sus disquisiciones, respalda la conveniencia de un examen conjunto, por otro lado no inédito. De por sí, el mismo reconocimiento que Schmitt otorgó a Strauss, afirmando que este fue quien mejor había comprendido "su intención original" al redactar El concepto de lo político ${ }^{39}$, o el mantenimiento expreso de la noción de "teología-política" en Strauss, para plasmar la cuestión medular que le había acuciado a lo largo de su trayectoria, dan pie a inquirir con más detalle la influencia mutua entre sus visiones. De manera preferente, tal y como se ha indicado al inicio del texto, recurrimos a los estudios que el profesor H. Meier dedicó a nuestros autores, en los que profundizó en los puntos mencionados.

\subsection{El "liberalismo" en Schmitt}

Las reflexiones que Strauss publicó tras la aparición de El concepto de lo político ${ }^{40}$ son las que arrojan mayor

\footnotetext{
39 H. Meier, Carl Schmitt, Leo Strauss y El concepto de lo político. Sobre un diálogo entre ausentes, Buenos Aires, Katz, 2008, p. 20.

40 "Comentario sobre El concepto de lo político" (1932), en ibidem, pp. 133-168.
}

material para ahondar en la comparación y el entrecruzamiento de impresiones, que siempre se mantuvo "en silencio". En este sentido, el libro de Meier: Carl Schmitt, Leo Strauss y el concepto de lo político (1998) sonoriza este diálogo, en tanto procede a detectar las variaciones que Schmitt introdujo en la tercera edición de su libro (1933), como reacción sigilosa a las puntualizaciones blandidas por Strauss ${ }^{41}$. Y su conclusión es nítida: Strauss forzó a Schmitt a explicitar el soporte teológico, incluso la dependencia, de su mentalidad política, que al cabo obedece a una profesión de fe. La enjundia del comentario straussiano descansa en la fragilidad desprevenida que descubre en el anti-liberalismo de Schmitt, por cuanto operaría desde premisas liberales: concretamente, desde la elevación de Hobbes como el "pensador político más grande", padre de la hipótesis del estado de naturaleza a partir de la cual el alemán construyó el criterio de "lo político", basado en la enemistad.

A través de esta ruta, la óptica de Strauss escala a un plano crítico superior. Si se pretende enmendar el liberalismo político, como desea Schmitt, hay que instalarse al margen del clima cultural de estirpe cientificista - orientado a autonomizar los saberes humanos en esferas diferenciadas-, que empieza a avanzar en el siglo XVII' ${ }^{42}$. Por ello, "lo político", en lugar de deslindarse meramente de otros ámbitos, ha de acabar absorbiéndolos, e izarse como indicador existencial decisivo. La categoría de enemistad ha de encontrarse, pues, incrustada en todo terreno de actividad humana -como al final propone Schmitt-, y emerge descarnadamente en el momento en el que nuestra vida queda expuesta a su exterminio. La traba que sigue advirtiendo Strauss se constata en el citado entronque del jurista con Hobbes, puesto que tan solo toma de este sus presupuestos de partida, y ni siquiera del todo. Y es que acudir al estado de guerra como paradigma de "lo político", por muy ilustrativo que sea, implica obviar el objetivo capital que encara Hobbes: superar dicho estadio para legitimar la necesidad racional de la autoridad política. Desde este punto de vista: "Hobbes es el pensador antipolítico por excelencia («político» entendido en el sentido de Schmitt)"»33.

Por añadidura, el asunto se agrava en virtud de la acusada lectura liberal que Strauss hace del inglés, más que por los poderes del Leviatán (que admite cierto margen de libertad hacia sus súbditos) por el giro individualista desde el que Hobbes configura su pensamiento. En consecuencia, la unidad límite mediante la que debe comprenderse la articulación del Estado la representaría el individuo, toda vez que su justificación viene dada por la defensa de su vida. Hobbes de hecho anticipa la figura del burgués que siglo y medio después delimitará Hegel, como el hombre "que no quiere abandonar la esfera privada no política, exenta de riesgo"44; en las antípodas del

$41 \quad$ El libro de Meier rastrea exhaustivamente los cambios entre la edición de 1933 y la de 1932, sin perder de vista la primera edición de 1927.

42 En el pensamiento de Strauss, la especialización científica no solo rompe con la mentalidad integradora de los antiguos, sino que se atreve a determinar qué es la naturaleza y a conquistarla con fines instrumentales.

43 H. Meier, Carl Schmitt, Leo Strauss y El concepto de lo político, op. cit., p. 147.

$44 \quad$ Ibidem, p. 61. 
acento existencial con el que Schmitt define el dominio de "lo político". No obstante, Schmitt continuará soslayando la nuclearidad que adquiere este individualismo, persistiendo en el enfoque político grupal, comunitarista -donde el individuo está presto al sacrificio por una causa mayor ${ }^{45}$-, sirviéndose únicamente en este tema (que no es sino el de la naturaleza humana) de lo que le resulta de provecho: el pesimismo antropológico.

El postulado de la maldad humana suele encajar mejor en el marco de las teorías conservadoras, de modo que a Schmitt le conviene argüir este supuesto (antiliberal) hobbesiano, alineándolo con su certidumbre de que "todas las teorías políticas propiamente dichas presuponen que el hombre es «malo» y lo consideran como un ser no solo problemático, sino «peligroso»" ${ }^{46}$. Sin embargo, aun en este punto, Strauss le reconviene -o, mejor- le incita a desvelar el estrato soterrado que anida en su creencia: el dogma del "pecado original". De ahí que -según se destaca-, las analogías teológicas de las nociones políticas hayan de interpretarse en términos de supeditación de estas sobre aquellas, más que de correspondencia o afinidad. La peligrosidad humana en Schmitt deja pues de remitir a un instinto primario animal, inocente, convirtiéndose en una auténtica maldad intelectual.

Dejando de lado los imprecisos paralelismos con Hobbes, Strauss se sumergirá en perfilar el trasfondo religioso de Schmitt que en, último extremo, anegaría el conflictivismo constitutivo de su pensamiento político, en lo que acaso suponga la mayor puesta en cuestión de la tesis schmittiana. La hipótesis no es anecdótica porque conlleva sostener que Schmitt no instrumentaliza la teología a efectos políticos ${ }^{47}$, sino todo lo contrario: instrumentaliza la política a efectos teológicos. En el análisis sobre su convicción de que las guerras perdurarán hasta el fin de los tiempos o -lo que es lo mismo- en que resulta imposible alcanzar un mundo pacificado, se daría prueba de dicha fundamentación teológica. Por descontado, la vituperación del liberalismo cosmopolita queda ligada a un enfoque despolitizado del mundo, ajeno a las hostilidades y a la relevancia de la enemistad en todo orden de $\operatorname{cosas}^{48}$. La negligencia de esta visión para Schmitt consistiría en suspender el sustrato "ontológico-existencial" ${ }^{49}$ de la realidad humana, ignorando el riesgo de la amenaza vital que dota de seriedad del mundo. Ahora bien, detrás del programa cosmopolita se vislumbra un peligro superior, el de la fe en el hombre

\footnotetext{
Schmitt afirma: "[...] es siempre la agrupación humana que marca la pauta; y de ahí que, siempre que existe una unidad política, ella sea la decisiva, la «soberana»", El concepto de lo político, op. cit., p. 68. 46 Ibidem, p. 90.

47 Tal y como por ejemplo suscribía P. Lucas Verdú: “Lo que le importó y acució fue utilizar e instrumentalizar los conceptos de la Teología para desarrollar su pensamiento", en "Carl Schmitt: interprete singular y máximo debelador de la cultura político-constitucional demoliberal", Revista de Estudios Políticos no 64 (nueva época) (abriljunio), p. 40.

48 Como anota Meier, es en esta cuestión -sobre la imposibilidad futura del Estado universal- donde "más cerca y más lejos" se halla Strauss de Schmitt (H. Meier, Carl Schmitt, Leo Strauss y El concepto de lo político, op. cit., p. 67). Más próximo, porque coincide en el juicio (la irremediabilidad del conflicto); más lejos, porque sus motivos son filosóficos: los interrogantes perennes no se pueden resolver.

$49 \quad$ Ibidem, p. 86.
}

o el endiosamiento humano, bajo el que se esconde el "enemigo providencial": el Anticristo.

Hasta aquí se entiende que Schmitt persevere en su esquema conflictual, aunque ya se manifieste el arraigo teológico de la misma. No obstante, el prisma teológico conducirá a Schmitt -tras el texto de Strauss- a inclinarse por un tratamiento no agonal ante la guerra. Ante la belicosidad humana se impone a fin de cuentas la necesidad de un orden, por más que este solo pueda sancionarlo una instancia extra-humana, divina. De esta manera, lo que demuestra Strauss es la subordinación en Schmitt de los contenidos de la política a la religión y, por extensión, su toma de postura inequívoca, su compromiso católico que -con independencia de sus contenidos, evidentemente reaccionarios, antiliberales- reintroducen la reflexión en un espacio de debate liberal, plural: en un apuesta política frente a otras. A partir de este momento dará igual ya que Schmitt considere que su envite no responda a una decisión libre (como si fuese una obligación derivada de la verdad revelada), por cuanto su lógica continúa "atada" al liberalismo o, quizá habría que decir, a la modernidad, si es que: "lo único que separa al historicismo de Schmitt del historicismo de sus contemporáneos liberales [...] es su fe" ${ }^{\circ}$.

El estudio de Strauss que glosa Meier comporta el doble interés de ofrecernos la lectura de un Schmitt encadenado al liberalismo y, al tiempo, de enfatizar la condición religiosa (incluso moral) más que política de su pensamiento. La teología política quedará así asociada al proyecto de una mentalidad moderna que retorna a fuentes premodernas (católicas) en las que acaso se halla justamente el germen de la modernidad. La importancia de la conclusión straussiana radica en que, aun formulada en 1932, mantiene su vigencia dada la nula modificación posterior que experimentan los planteamientos de base de Schmitt. En cambio, no es inoportuno recordar cómo la mirada straussiana evolucionó al emigrar a Estados Unidos, flexibilizando su conservadurismo filo-autoritario hacia disposiciones más liberales, sin menoscabo de su clasicismo. Quizá su recalcitrante provocación por exhibir la precariedad del envite antiliberal de Schmitt se hubiese modulado, de haberlo escrito quince años después, y quizá a este respecto sea expresivo el silenciamiento del propio diálogo, nunca reconocido "como tal" ${ }^{51}$. En cualquier caso, tanto para un Strauss joven como para uno maduro, Schmitt nunca se le aparecerá como un filósofo, quedándose siempre en lo que fue: como un pensador afincado del lado de la revelación, desentendido de las enseñanzas de Atenas; como un ciudadano, como un político, como un maestro de políticos - es decir, como un sofista-, pero jamás como un filósofo y ni siquiera como un filósofo político ${ }^{52}$ : al cabo, como un teólogo de la política.

\subsection{La religiosidad en Strauss}

Dicho esto, resta la duda de explicar por qué Strauss, en su estatus de filósofo, se refirió incluso en su épo-

\footnotetext{
Ibidem, p. 125

51 Ibidem, p. 22.

52 Donde su obra esotérica (no publicada) refuerza más que matiza la parte exotérica (M. Salaregui, Carl Schmitt: pensador español, Madrid, Trotta, 2016, pp. 241 y ss.).
} 
ca más tardía al problema teológico-político como "el tema" de sus investigaciones ${ }^{53}$. Meier se dedicó asimismo a indagar sobre este interrogante en Leo Strauss y el problema teológico-político (2000), invitando a una respuesta tentativa: la filosofía no cobra conciencia de su magnitud teórica, de su dimensión -diríamos- veritativa, sino haciéndose cargo del desafío que le lanza la teología-política. La obra de Strauss oscila entre dos extremos: la razón y la revelación, o Atenas y Jerusalén, explorando sus puntos de contacto y préstamos recípro$\cos ^{54}$. Sin embargo, gran parte de sus "investigaciones" se centran en solo uno de estos polos -el de la fe-, acaso para despojar a la filosofía de toda apoyatura religiosa, aunque apurando tanto los argumentos que a menudo parece debilitarla ${ }^{55}$, más aún cuando lo que está en juego es la organización política de la ciudad.

Resulta crucial enmarcar la interpretación del "problema" en sus lindes correctas, no como una rivalidad entre la teología y la política (que presentan un grado de fusión análogo al de Schmitt) ${ }^{56}$, sino entre la religión y la filosofía, pero en el que la teología-política aglutina la carga dilemática. Y ello porque existen motivos racionales que dan cuenta de la coherencia de la fe en la revelación -con inmediatas repercusiones sobre la vida político-práctica- y porque, a su vez, la filosofía afronta severas dificultades para fundamentar racionalmente la necesidad de su actividad; a lo que cabe agregar las implicaciones que arrastra el triunfo de un pensamiento moderno (historicista, liberal, ilustrado) que, lejos de haber solventado tales cuestiones, las ha complicado, propiciando la instauración de una "segunda caverna", con antecedentes en la teología cristiana medieval ${ }^{57}$.

De lo que se trataría, pues, para resolver "el problema" - cuando menos para aclararlo-, es de escapar en primer lugar de esta "segunda caverna" a través de un "contraproyecto" opuesto al de Hobbes. Así como este articuló, con el Leviatán, un tratado teológico-político que relega las creencias a un plano privado y legitima racionalmente las "prerrogativas divinas de omnipotencia e inescrutabilidad" de un Dios mortal ${ }^{58}$, habría que emprender el proyecto de un tratado antagónico que partiese de la significación originaria de la ley, constitutivamente adherida a la revelación, y que posteriormente -en un sentido argumental contrario al de Hobbes- desplegase su justificación racional. Este propósito, como se adelantó, se encuentra detrás del libro de Strauss, Filosofía y ley, que rescata igualmente el mismo rumbo que tomó Platón en Las Leyes. Además, la circunstancia

53 Según confiesa en 1964, en el prólogo de la edición inglesa de su ensayo primerizo: La crítica de la religión en Spinoza.

54 Sobre esta materia, aunque desde un enfoque distinto, siempre conviene evocar la obra de L. Shestov, Atenas y Jerusalén, Madrid, Hermida, 2018.

55 H. Meier, Leo Strauss y el problema teológico-político, Buenos Aires, Katz, 2006, p. 58.

56 Aun, de nuevo, por causas dispares: a Strauss, en tanto filósofo, no le importaría "el contenido de la revelación" (H. Meier, Leo Strauss y el problema teológico-político, op. cit., p. 68), cuanto el impacto de la fe sobre la política e incluso la vida filosófica.

57 M D. Yaffe, "Leo Strauss y la dimensión teológica de la filosofía política", La Torre del Virrey: revista de estudios culturales, $\mathrm{n}^{\circ} 6$, 2009, p. 101.

58 A. Lastra, "Modernidad y conservadurismo (Carl Schmitt y Leo Strauss)", Daimon: Revista de filosofia, n 13, 1996, p. 122. de que la vocación filosófica hacia el saber pudiese rebatir la conducta devota de la obediencia, quedaba en principio resuelta por la vía de Alfarabi: los preceptos político-religiosos encierran una utilidad pública -sobre el gobierno de la ciudad-que el filósofo intuye, mientras cultiva en privado su propia disciplina, ajena a las creencias (y no la pone por tanto al servicio de la política, como en la modernidad).

Pero Strauss -y he aquí la perpetuación del "problema"- vuelve una y otra vez sobre la materia, desde nuevos ángulos y contornos. Meier se detiene así en el texto publicado en 1948, Reason and Revelation, donde se trasluce la pregunta (de signo moral) que a Strauss le intriga: ¿cómo se ha de vivir?, ¿cuál es la vida correcta? Su discurso sugiere que si la opción por la vida filosófica-de persecución teórica de conocimiento- no responde a motivos más sólidos que a los que obedece la vida práctica -de acatamiento a unas normas que se presumen verdaderas- esta última opción se revela más coherente: la resolución del creyente brinda más ventajas a todos los efectos. Y sin embargo, tras esta conclusión, late la sospecha de que a Strauss: "lo único que le importa es la coherencia de la filosofía"59. Estaríamos pues ante una especie de circunloquio, típico del estilo straussiano, guiado por el cuestionamiento de la necesidad de la filosofía, que desembocará en una recuperación de su papel, en tanto la revelación tampoco es evidente. Dicho en palabras de Strauss:

La posibilidad de revelación implica la posible falta de sentido de la filosofía. Si la posibilidad de la revelación queda como una cuestión abierta, la importancia de la filosofía también queda como una cuestión abierta. [...]. La filosofía no puede permitirse ser modesta ${ }^{60}$.

Este extracto es esencial para apreciar la desavenencia irreconciliable entre filosofía y teología política, tanto más si como de inmediato apunta Meier: "la refutación de la fe en la revelación se vuelve una tarea indispensable para la filosofía".

Incluso así, hay todavía un hueco intermedio para la labor del filosofo político, que no ejerce de mediador pero que sí conoce el alcance efectivo de las normas y creencias, sabe que no todos los ciudadanos pueden ser filósofos, aunque sí creyentes, y que hay asuntos en los que razón y fe intersectan, puesto que en cualquier caso todos los individuos aspiran a ser felices. Meier traza así varias líneas de conexión - que afectan a la vida en comunidad, al discernimiento moral, a los límites del conocimiento o a la propia naturaleza de los dioses-que abren un espacio de enriquecimiento mutuo, aunque el abismo sea infranqueable. Porque aun incluso en sus líneas más medidas ${ }^{61}$, Strauss se opondrá a la concepción de una "philosophia ancilla theologiae", tanto como de

\footnotetext{
59 H. Meier, Leo Strauss y el problema teológico-politico, op. cit., p. 68.

$60 \quad$ Ibidem, p. 74

${ }^{61}$ Verbigracia, cuando escribe: "Nadie puede ser a la vez filósofo y teólogo o, para el caso, algo que esté por encima del conflicto entre filosofía y teología, o una síntesis de las dos. Pero cada uno de nosotros puede y debe estar abierto a la una o a la otra, el filósofo abierto al reto de la teología, o el teólogo abierto al reto de la filosofía" (L. Strauss, "The Mutual Influence of Theology and Philosophy" en The Independent Journal of Philosophy vol. III, Viena, 1979, p. 111).
} 
una filosofía sierva de la política. Ahora cabe entender por qué Meier, al reseñar el Glossarium de Schmitt, habla del "filósofo como enemigo" por cuanto para un estricto "teólogo de la política" no es posible entablar conversación alguna con la filosofía, siempre sensible -por definición en Strauss- al escepticismo.

Limitados a la escala política, para Strauss es legítimo e incluso obligado que el ciudadano decida, mientras al filósofo genuino se le permita libertad, preferiblemente en privado; para Schmitt en cambio resulta impensable -acaso sencillamente ocioso- dirimir cualquier cuestión más allá del terreno teológico-político, sin atender al horizonte de sentido y orden que configura la realidad. Según se ha insistido, el mero contraste de la recepción de Hobbes en ambos autores bastaría para percibir sus disimilitudes políticas ${ }^{62}$; aun aceptando el rango teológico político del Leviatán, las semejanzas se detendrían aquí. No será preciso recordar el componente utilitario, anti-aristocrático e historicista que Strauss desvela en esta obra, al punto de que en Hobbes: "el ejemplo histórico es superior al precepto filosófico". Pero sí merece la pena constatar el paso que acomete Schmitt, dogmatizando el potencial mítico del Leviatán, custodiándole de toda crítica, y clamando por su actualización religiosa contemporánea ${ }^{63}$. Y aun así, no es imposible todavía captar -bajo la interpretación de Strauss- el pálpito de un liberalismo antiguo en Schmitt que, justamente por su fe católica, está "a la búsqueda [...] del verdadero bien, de un orden (concreto) extraído de un saber tan imparcial como la filosofía política antigua" ${ }^{64}$.

\section{Conclusión}

Desde el punto de vista de la historia de las ideas y el poder, el concepto de "teología política" resulta, si no infrecuente, todavía impreciso. Su empleo continúa, en gran medida, asociado a la ascendencia del pensamiento medieval sobre el moderno, al estudio de las relaciones entre la Iglesia y el Estado y, en última instancia, al eco salvífico de las ideologías contemporáneas, básicamente en el totalitarismo. Según esta óptica, el alcance de la teología política habría perdido fuelle (cuando no habría desaparecido) tras la II Guerra Mundial y su recuperación reciente vendría dada por el impacto político del islam ${ }^{65}$. Estaríamos aquí ante una interpretación de la secularización cuya clave radicaría en el declive de la teocracia en Occidente. Este planteamiento -que plasma lo que se denomina visión whig de la historia- afirma que a partir del siglo XVII dio inicio la

${ }^{62}$ En el intervalo de dos años, Strauss y Schmitt publicaron sendas monografías sobre el inglés: La filosofia politica de Hobbes: su fundamento y su génesis (1936) y El Leviatán en la teoría del Estado de Thomas Hobbes (1938), respectivamente.

63 A. Lastra, op. cit., p. 122 y ss.

${ }^{64}$ A. Rivera García, op. cit., p. 98

65 No sería correcto obviar la proliferación de estudios durante la última década en torno a la "teología política", no solo por el interés que viene despertando el pensamiento de C. Schmitt, tanto más en un contexto de polarización política (2015-2020). Asimismo, el enfoque paulista, articulado desde la "teología política" de Jacob Taubes, ha ido ensanchando su eco, impulsado por su recepción en autores de notable ascendencia en la filosofia política contemporánea (Alain Badiou, Giorgio Agamben, etc.). Igualmente, aun desde un prisma más historiográfico, cabe aludir a la creciente divulgación de la obra de Jan Assmann.
"Gran Separación"66 gracias a la cual la religión dejó de influir sobre la política, acudiendo -al igual que los autores examinados- a Thomas Hobbes, en tanto razonó la legitimación del poder con argumentos ajenos a la revelación divina. Ciertamente, el apuntalamiento tardó tres siglos en imponerse, toda vez que autores como Rousseau, o el idealismo filosófico alemán, mantuvieron viva la nostalgia por el "mundo religioso". Además, el influjo de la religión no se redujo a finales del siglo XVIII a la dimensión sentimental o simbólica de la cultura, sino que pervivió incluso en el delineamiento del horizonte de la ética kantiana ${ }^{67} \mathrm{o}$ en la fundamentación de la metafísica hegeliana, cuyo sistema -no sin motivo- se entiende a menudo como un "cristianismo secularizado". Bajo esta estela, el siglo XIX conoció una relectura de la teología protestante y del judaísmo conciliada con el liberalismo burgués, la tolerancia y los valores optimistas del progreso, tendencia que quedó quebrada con el estallido de la I Guerra Mundial. Fue entonces cuando reflotó el espíritu mesiánico de las "religiones políticas", inspiradas en la emergencia del "hombre nuevo". Hubo pues que esperar a 1945 para ver consumada la desacralización del espacio político en Occidente.

Este tratamiento, obviamente, no concuerda con la mentalidad de los autores analizados. Acaso quepa ubicar el pensamiento de Schmitt en ese momento de afloramiento redentorista de los años treinta; sin embargo el conflictivismo realista de su tesis -tanto más en aquel periodo- no se ajusta al tono de una mística emancipadora. De hecho, lo que Schmitt presentó fue una nueva concepción de teología política ${ }^{68}$, apenas basada en la actualización de los razonamientos teocráticos, cuanto más bien ligada a la comprensión cabal de las ideas y las formas políticas del presente. La cuestión que desarrolla es la de la resacralización del mundo político debido a que a su parecer este resulta incompresible -más aún: inconcebible- despojado de categorías teológicas, lanzando un desafío intelectual al Occidente contemporáneo aún por resolver ${ }^{69}$, y que incluso ha llegado seducir a corrientes postmarxistas en virtud, por

66 M. Lilla, "The Politics of God", The New York Times Magazine $(19 / 08 / 2007)$.

${ }_{67}$ Como es sabido, la ética de I. Kant no presupone la idea de Dios, pero sí que se orienta hacia la religión: "la ley moral conduce a la religión, esto es, al reconocimiento de todos los deberes como mandamientos divinos, no como sanciones, como órdenes arbitrarias de una voluntad ajena, contingentes en si mismas, sino con leyes esenciales de toda voluntad libre en sí misma, pero que, de todos modos, se han de entender como mandamientos del Ser supremo" (F. Copleston, Historia de la Filosofia vol. VI, Barcelona, Ariel, 1996, p. 322).

68 "El tema, tal y como hoy suele presentarse, fue introducido por Carl Schmitt en 1922" (A. d'Ors, "Teología política: una revisión del problema", Revista de estudios políticos, no 205, 1976, p. 42).

69 En sintonía con los ensayos de liquidación teológica y científica de la teología política, acometidos por Peterson y Blumenberg, Yves Charles Zarka afrontó el mismo propósito desde un ángulo filosófico-político, con el fin de erradicar el dominio de lo sagrado del espacio político. Su argumentación defiende el carácter histórico y precario de los conceptos políticos y, a su vez, vela por la despolitización de la teología sin que ello suponga rebatir la importancia social de la religión. Para ello acude a la noción de soberanía democrática en Alexis de Tocqueville, construida "desde abajo" y que puede dividirse y transformarse, perdiendo en todo caso los atributos divinos del modelo absoluto que todavía despuntaban en Rousseau. Con todo, el autor admite que el "proyecto [de crítica radical de toda teología política] es aún bastante utópico hoy día" (Y. C. Zarka, "Para una crítica de toda teología política", Isegoría: Revista de filosofia moral y política, $\mathrm{n}^{\circ} 39,2008, \mathrm{p} .47$ ). 
de pronto, de la refutación de la premisa liberal que separa a la política de la economía; todo es política.

Igualmente, pretender acoplar la obra de Strauss y de su aproximación al problema de la teología política bajo la clave de la "Gran Separación" sería del todo punto improcedente. Por el contrario, la carga de su pensamiento se vuelca en impugnar la lógica de una modernidad supuestamente secularizada, que precisamente comienza a desorientarse en su época fundacional, cuando se da inicio la politización de la filosofía ${ }^{70}$. La reivindicación straussiana de un plano de reflexión teórico, amarrado al racionalismo premoderno, le permite contemplar la vida práctica-de la política, de las normas, de las leyes, de la religión- como un lugar desplazado, pero no irrelevante. De hecho, al verdadero filósofo político le corresponderá escrutar sobre los confines del bien y del mal, sin perder por ello de vista el rumbo y, al cabo, las decisiones que se toman en la ciudad. Ahora bien, de aquí a que el filósofo se subsuma a la perspectiva del teólogo media un paso -el que va de la libertad a la obediencia- que Strauss no está dispuesto a dar.

Finalmente, ante las preguntas planteadas al inicio del texto, cabe aventurar dos conclusiones: i) la relación conceptual entre religión y política resulta en efecto inescindible en los autores tratados. Ello no les impide detectar divergencias significativas sobre el alcance y uso de conceptos tales como "soberanía" o "ley": la analogía no es identidad; ii) por efecto del escepticismo socrático, la reflexión filosófico-política es susceptible de desprenderse levemente de contenidos teológicos -mejor dicho: de distanciarse- en la obra de L. Strauss. Cuestión distinta será interrogarse entonces por su relevancia.

\section{Bibliografía}

Aragón, M., "La crisis de la democracia constitucional: ¿un pasado que amenaza volver?”, Revista de Libros (abril), 2019, disponible en la siguiente URL: [https:/www.revistadelibros.com/articulos/la-crisis-de-la-democracia-constitucional-unpasado-que-amenaza-volver].

Copleston, F., Historia de la Filosofia, vol. VI, Barcelona, Ariel, 1996.

d' Ors, Á.,: "Teología política: una revisión del problema”, Revista de estudios políticos, n 205, 1976, pp. 41-80.

Galindo Hervás, A., “¿Autonomía o secularización? Un falso dilema sobre la política moderna”, en Mate, R. y Zamora, J.A., Nuevas teologías políticas: Pablo de Tarso en la construcción de Occidente, Madrid, Anthropos, 2006, pp. 117-138.

García Alonso, M., "Carl Schmitt o la imposibilidad de una política secularizada”, Isegoría: Revista de filosofia moral y política, $n^{\circ} 32,2005$, pp. 235-243.

Gómez Orfanel, G., "Carl Schmitt y el decisionismo político", en Vallespín, F., Historia de la teoría politica, vol. 5, Madrid, Alianza, 1995, pp. 243-272.

Hobbes, T., Leviatán, Madrid, Alianza, 1986.

Kervégan, J. F., ¿Qué hacemos con Carl Schmitt?, Madrid, Escolar y Mayo, 2013.

Lastra, A., "Modernidad y conservadurismo (Carl Schmitt y Leo Strauss)“, Daimon: Revista de filosofia, n 13, 1996, pp. 115128, disponible en la siguiente URL: [https://revistas.um.es/daimon/article/view/8361].

Lilla, M., "The Politics of God", The New York Times Magazine (19/08/2007), 2007. disponible en la siguiente URL: [https:// www.nytimes.com/2007/08/19/magazine/19Religion-t.html].

Lucas Verdú, P., "Carl Schmitt: interprete singular y máximo debelador de la cultura político-constitucional demoliberal”, Revista de Estudios Políticos n 64 (nueva época) (abril-junio), 1989, pp. 25-92.

Luri, G., Erotismo y prudencia: Biografia intelectual de Leo Strauss, Madrid, Encuentro, 2012.

Meier, H., Leo Strauss y el problema teológico-político, Buenos Aires, Katz, 2006.

-, Carl Schmitt, Leo Strauss y El concepto de lo político. Sobre un diálogo entre ausentes, Buenos Aires, Katz, 2008.

-, “QQué es la teología política?: introducción a un concepto controvertido", La Torre del Virrey: revista de estudios culturales, $\mathrm{n}^{\circ}$ 6, 2009, pp. 89-93.

Pardo, J. L., Estudios del malestar: Políticas de la autenticidad en las sociedades contemporáneas, Barcelona, Anagrama, 2016.

Pendás, B., "Leo Strauss, ideas sin contexto", Revistas de Libros n 125 (mayo), 2007, disponible en la siguiente URL: [https:// www.revistadelibros.com/articulos/leo-strauss-ideas-sin-contexto].

Rivera García, A., "Secularización y crítica del liberalismo moderno”, Isegoría. Revista de filosofía moral y politica, n 39 (juliodiciembre), 2008, pp. 79-100.

-, "Blumenberg y el debate sobre la Secularización”, Revista Eikasia, no 45, julio, 2012, pp. 237-244.

Salaregui, M., Carl Schmitt: pensador español, Madrid, Trotta, 2016.

Schmitt, C., El concepto de lo político, Madrid, Alianza, 1998.

-, Teología política, Madrid, Trotta, 2009.

Strauss, L., "The Mutual Influence of Theology and Philosophy”, The Independent Journal of Philosophy vol. III, Viena, 1979, pp. 111-118.

-, "The Three Waves of Modernity", en Gildin, H. (ed.), An Introduction to Political Philosophy: Ten Essays by Leo Strauss, Detroit, Wayne State University Press, 1989, pp. 81-98.

-, ¿Qué es filosofía politica?, Madrid, Alianza, 2014.

Vallespín, F., "La vuelta a la tradición clásica", en Vallespín, F., Historia de la teoría política, vol. 5, Madrid, Alianza, 1995, pp. 354-396.

Villacañas, J. L., "La leyenda de la liquidación de la teología política”, en Schmitt, C., Teología política, Madrid, Trotta, 2009, pp. 135-180.

70 B. Pendás, "Leo Strauss, ideas sin contexto", Revistas de Libros n ${ }^{\circ}$ 125 (mayo), 2007. 
Yaffe, M. D., "Leo Strauss y la dimensión teológica de la filosofía política", La Torre del Virrey: revista de estudios culturales $\mathrm{n}^{\mathrm{o}}$ 6, 2009, pp. 95-102.

Zarka, Y. C., "Para una crítica de toda teología política”, Isegoría: Revista de filosofía moral y política n 39, 2009 , pp. $27-47$. 